\title{
ASCENSÃO E DECLINIO DA ARTE DA CANTARIA ESTUDO DE CASO: PONTE DA CADEIA
}

\author{
Marcos Aurélio Todorov Silva', Thiago Bomjardim Porto² \\ 1 - Arquiteto e Urbanista, Consmara Engenharia; 2 - Engenheiro Civil, Professor PUC Minas \\ marcos.todorov@consmara.com.br
}

\begin{abstract}
Resumo: A arte de lavrar a rocha em variadas formas geométricas e figurativas foi amplamente usada no século XVIII, tinha como finalidade ornamentar e estruturar edificações de diversos usos e formas. Mas esta arte foi se tornando cada vez menos usual, devido ao surgimento de materiais que possibilitavam agilidade na construção e por serem economicamente mais viáveis. Assim com o desuso da cantaria, as técnicas e seus executores foram diminuindo e se perdendo no adentrar do século XX. A origem da arte da cantaria torna-se vulgar quando comparados com os atuais produtos tecnológicos, neste contexto mercadológico e modista é preciso resgatar o reconhecimento da obra de arte, e esse resgate se dá através da comunidade em que ela se insere, o envolvimento efetivo, tanto através do conhecimento técnico como cultural dos elementos pétreos, trará o empoderamento necessário para o surgimento de uma ação mais efetiva na conservação da matéria e restauração das obras de arte. O objeto tomado como referência de estudo é a Ponte da Cadeia, localizada na cidade de São João del Rei/MG, datada do ano de 1798, em pedra e cal, com cantaria miúda de picão em todas suas faces e lados.
\end{abstract}

Palavras Chave: Ponte da Cadeia, cantaria, empoderamento, comunidade, projeto de restauração

Abstract: ASCENSION AND DECLINE OF STONEWORK ART. CASE STUDY: PONTE DA CADEIA. The art of plowing a rock in various geometric and figurative forms was widely used in the eighteenth century, its purpose was to decorate and structure buildings of various uses and shapes. But this art became less and less usual, due to the appearance of materials that allowed agility in construction and because they were economically more feasible. Thus with the disuse of the Stone work, the techniques and their executors were diminishing and getting lost in the entering of XX century. The origin of the stonework art becomes vulgar when compared with the current technological products, in this marketing and modiste context it is necessary to rescue the recognition of a work of art, and this rescue takes place through the community in which it is inserted, either an effective involvement throught he technical and cultural knowledge of the Stone elements, will bring a necessary empowerment to the emergence of a more effective action in a matter conservation and restoration works of art. The Bridge of the Chain is the object taken as reference, located in the city of São João del Rei / MG, dated from 1798, in stone and lime, with a little of abrasión Stone work on all its faces and sides.

Keywords: Chain Bridge, masonry, stonework, empowerment, community

\section{INTRODUÇÃO}

Material rico em abundância, acessível, e de beleza natural, a pedra em seu estado bruto é matéria prima presente em várias construções e objetos, acompanha o homem desde a pré-história, quando bem cuidada, tem vida longa, quase perene e registra a história das civilizações.

Sua brutalidade aos poucos se molda nas mãos de exímios artistas, e a forma bruta se transforma em delicados ornatos, criando diálogos entre a resistência enquanto estrutura e a suavidade enquanto ornamentação.

Teve acesso a todos os estilos da arquitetura, trazendo imponência, todavia se torna vulgar com a chegada da industrialização e as importações de materiais tecnológicos, o que passa a proporcionar maior agilidade na construção civil. O modo de construir tomará novos rumos e o declínio era certo.

A arte da cantaria não constituía apenas uma especificidade da arquitetura, ela era, e ainda é, um testemunho das próprias relações sociais que se estabeleciam nas comunidades, importância que foi se perdendo e a degradação de inúmeras obras em cantaria, de valor artístico e cultural, foi se vulgarizando e deixando de estabelecer vínculos com a comunidade local, desse modo a leitura espacial e o objeto tiveram sua compreensão e importância comprometidas, uma vez que os suportes físicos da memória das cidades são apagados lentamente, dando lugar a construções tecnológicas que não dialogam e não respeitam o meio preexistente.

Iniciativas de emergência são necessárias para resgatar e garantir a permanência do objeto enquanto identidade cultural e social, a preservação e conservação de monumentos em cantaria, pode ser intensificada com participação efetiva da comunidade a qual é parte integrante da importância não somente física, mas também afetiva e social do meio em que está inserida.

\subsection{Cantaria -Legado Subjugado}

A arte de lavrar a rocha, o trabalho com a pedra para a construção, e a manutenção da obra concluída ainda é um conhecimento de poucos. Mesmo com o grande número de edificações e obras existentes, é um desafio entre profissionais da área ou nos meios acadêmicos a conservação da cantaria. Por se tratar de uma técnica usada na elaboração de sistemas estruturais e também para elementos decorativos, sua discussão permeia por diferentes âmbitos de conhecimento. Alguns profissionais atribuem a cantaria à esfera arquitetônica, esta, no entanto, a partir da era modernista, tende a opor-se aos elementos decorativos, deixando-os em um 
âmbito de simplicidade das formas. Claro, este fato não é unanimidade, como é o caso de Sylvio de Vasconcelos que em 1958, realiza um estudo a esse respeito e produz a obra intitulada Arquitetura no Brasil: sistemas construtivos (Belo Horizonte: Escola de Arquitetura/UFMG, 1958). Após o pioneirismo de VASCONCELOS (1958), surgiram outras obras, especialmente na década de 80 , as quais, impulsionaram outros autores, tais como: GAMA (1983);VARGAS (1995);KATINSKY (1993), KATINSKY (1998), MOTOYAMA (2004), dentre outras.

Mas, apesar dos estudos e preocupações sobre a arquitetura brasileira surgirem timidamente, as questões relativas às técnicas de cantaria ainda ficam em segundo plano nas pesquisa e trabalhos, mesmo em Minas Gerais, que sendo um berço rico nestas técnicas durante o século XVIII, a discussão e manutenção da arte ainda são pouco valorizadas e estudadas. $O$ que pode ser observado nas documentações a respeito da arte da cantaria setecentista mineira, a qual é variada, porém extremamente incompleta. Os documentos mais tradicionais arquivados trazem registros sobre a administração das obras e muito pouco sobre a técnica construtiva (SILVA, 1994). Atualmente para se obter um registro ou uma evidência mais eficaz de como eram executadas as técnicas da cantaria é preciso buscar as informações in loco, e tais técnicas só podem ser "lidas" através de minuciosa análise de cada caso, é preciso quebrar barreiras e tabus para se obter tal eficiência, abrangendo disciplinas em variados níveis, como a historiografia, arqueologia, geologia e qual mais for necessária.

\subsection{A Arte da Cantaria}

Os registros mais conhecidos de construções em cantaria ou pedras aparelhadas de forma regular, aparecem na civilização egípcia (3.000 a.C.), apesar de haver na Europa um legado de grandes monumentos em pedra ou megalitos, localizados na Península Ibérica e datam aproximadamente 5000 a.C., no entanto as pirâmides são os exemplos mais conhecidos pela humanidade da arte da cantaria, como por exemplo as três grandes pirâmides localizadas a cerca de $18 \mathrm{~km}$ de Memphis, que datam de cerca de 2.600 a.C., Quéops" Quéfren e Miquerinos (veja figura 1).

No século VI a.C., época das famosas conquistas romanas, construtores acompanhavam os soldados nas batalhas, com a finalidade de reconstruir o que era perdido durante os confrontos, esse grupo de construtores, artesãos da cantaria, deram início aos

${ }^{1}$ A Pirâmide de Quéops, também conhecida como a Grande Pirâmide, é o monumento mais pesado que já foi construído pelo homem. Possui aproximadamente 2,3 milhões de blocos de rocha, cada um pesa em torno de 2,5 toneladas; com mais de 146 metros de altura. primeiros canteiros da história. No Brasil, apesar do uso de esculturas em pedra bruta a partir do século $\mathrm{XVI}$, o ápice e a consolidação da arte da cantaria, acontece, principalmente em Minas Gerais no século XVIII. Costa (2002, p. 37) menciona que nos dois primeiros séculos (séculos XVI e XVII), a cidade do Rio de Janeiro utilizava fartamente o granito com adornos em sequências ritmadas das ombreiras e vergas de portas, marcando assim a perspectiva urbana daquela época. A arte da cantaria é uma herança de canteiros portugueses, porém, em território brasileiro, adquiriram peculiaridades conforme a região de execução, mérito dos artistas locais e sua criatividade.

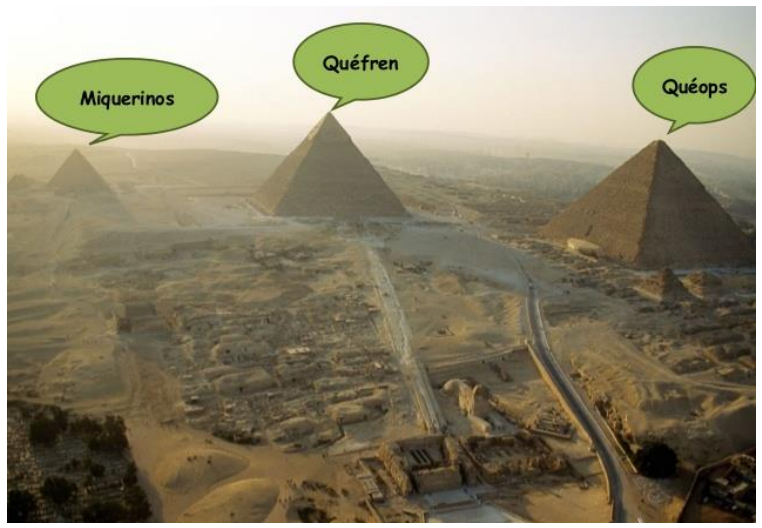

Figura 1. As Pirâmides de Gizé:Quéops, Quéfren e Miquerinos. Fonte: http://www.sohistoria.com.br/ef2/egito/piramides.php - 30/08/2016

Em 1549, Tomé de Souza, primeiro governador geral da colônia trouxe Luís Dias para o Brasil, o qual era um mestre da cantaria, e durante este período da colonização era comum que os projetos viessem prontos de Portugal, principalmente os projetos de cantaria, executados com Calcário Lioz, (veja figura 2), que também era importado de Portugal. Não houve um estilo específico de edificação na qual a cantaria era empregada, foi amplamente utilizada para as construções civis, militares e religiosas.

Em Minas Gerais as expressões mais significativas, surgiram em maior quantidade nas chamadas "Vila do Ouro", devido à descoberta do ouro na Capitania de Minas Gerais, em 1698, dentre estas vilas marcadas pela arte da cantaria, podemos destacar Ouro Preto, Diamantina, Serro, São João del Rei, dentre outras.

As edificações em pedra argamassada ou seca, pedra sobre pedra, que não utilizavam argamassa, foram surgindo aos poucos. Durante este período as alvenarias eram executadas com blocos avulsos de canga, como era chamado o minério de ferro, ora eram cobertas com argamassa de terra e cal, porém quando as peças de canga eram entalhadas, o acabamento era rústico. 
Em uma segunda fase, os quartzitos foram amplamente utilizados, principalmente nas partes nobres das edificações. Eram aparentes com acabamento refinado, sendo o principal registro o Palácio do Governador em Vila Rica,(veja figura 3), datado entres os anos de 1735 e 1738, obra atribuída ao engenheiro militar José Fernandes de Alpoim.

Já a terceira fase atribui-se às construções que surgiram por volta de 1755 com o emprego do esteatito, conhecido como pedra-sabão, de características que permitiam a ousadia de formas nos adornos.

A consolidação da arte da cantaria, que deu origem a diversas tipologias arquitetônicas em Minas Gerais, deu-se durante o século XVIII, graças ao trabalho coletivo de mestres portugueses e a primeira geração de artistas mineiros, os quais inovaram e deram identidade brasileira à arte da cantaria mineira.

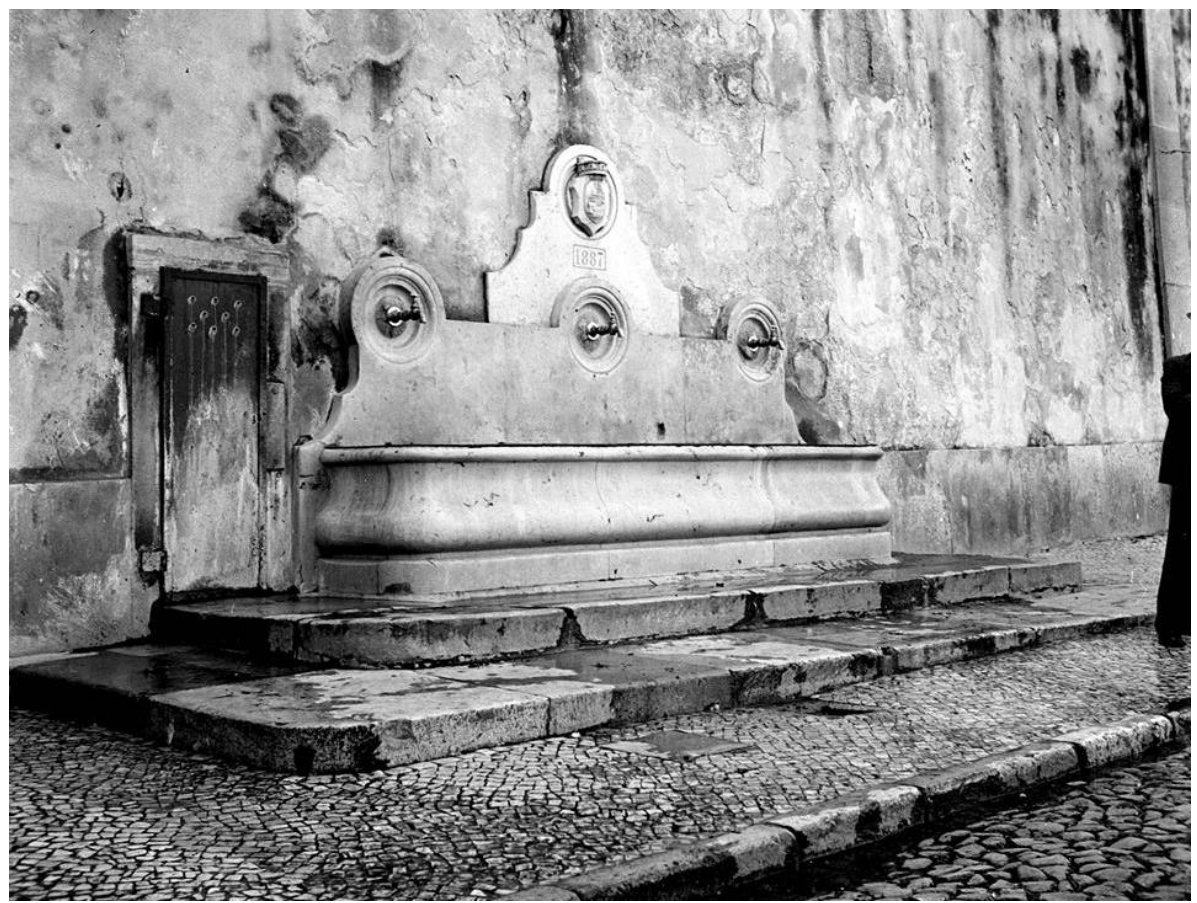

Figura 2. Chafariz de Santa Ana - Largo do Mastro. Autor: Fernando Martinez Pozal - S/D

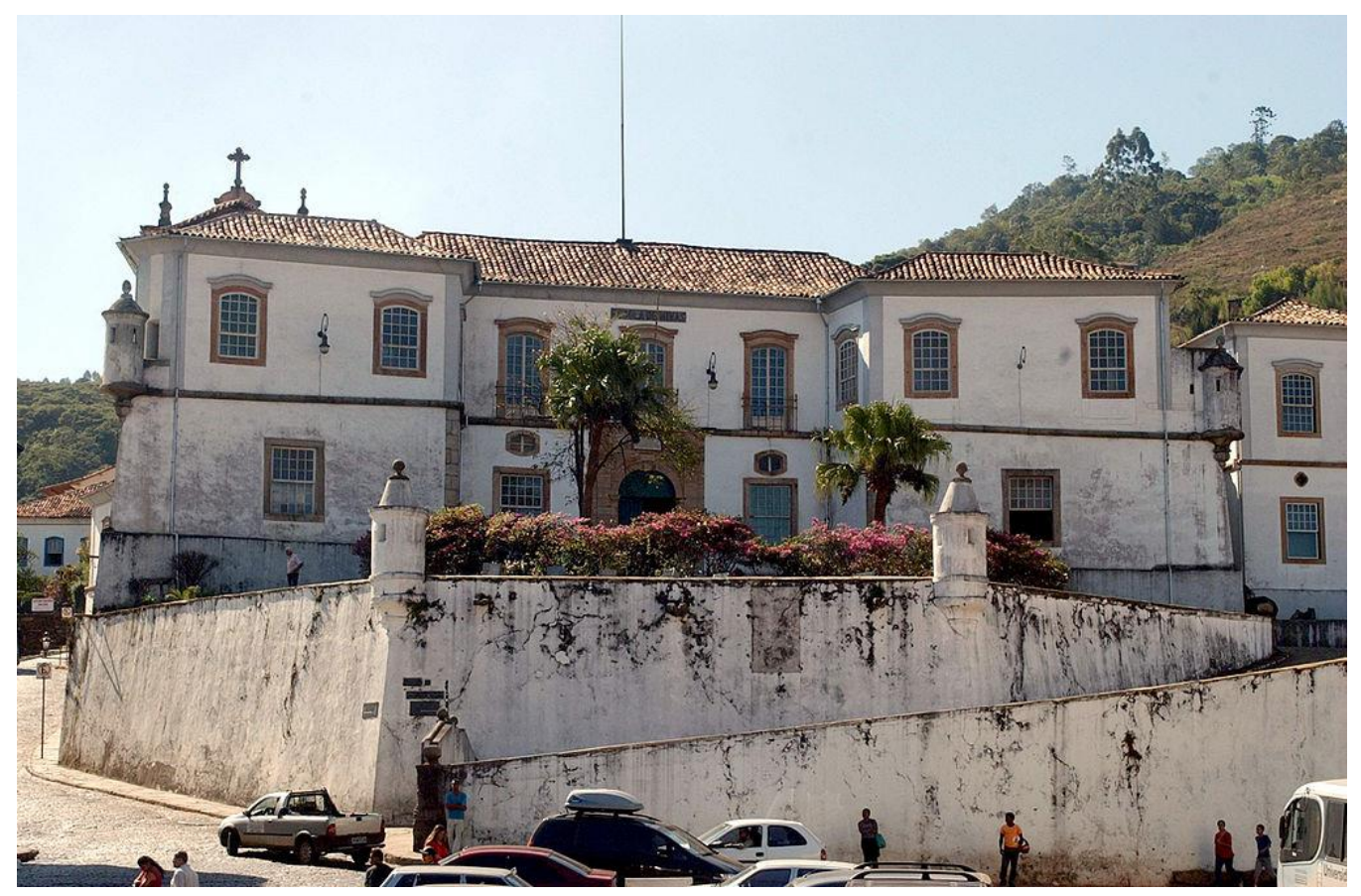

Figura 3. Palácio do Governador - Ouro Preto/MG. Autor desconhecido - S/D 


\subsection{O Declínio}

Apesar das obras de cantaria expressarem beleza, durabilidade, segurança, dentre outros atributos, ainda nos éculo XVIII ela foi paulatinamente sendo substituída por alvenaria de tijolo e os relevos moldados com argamassa de cal, gesso e areia.

Mas o declínio da arte da cantaria se dá efetivamente quando associado aos fatores econômicos e sociais, tais como a racionalização dos processos construtivos, com extinção das antigas organizações de ofícios mecânicos (decretada pela Constituição de 1822), e a intensa imigração de "operários da construção" oriundos da Alemanha e da França, onde a Revolução Industrial já transformara a Arte da Construção.

Logo, sem os trabalhos dos canteiros, que cada vez se tornavam mais raros, a arte da cantaria começa a ser substituída pelo metal e concreto. As ferramentas artesanais foram sendo substituídas pelas máquinas, a energia humana perdeu lugar para a energia motriz e a Revolução Industrial transformou a estrutura e valores da sociedade através da notável evolução tecnológica.

Os novos valores atendem cada vez mais as necessidades momentâneas, e o que era sofisticado, torna-se vulgar.

E contrariando o pensamento de Cesare Brandi (1963), a origem retorna a ser vulgar quando comparados com os atuais produtos tecnológicos, e neste contexto mercadológico e modista, é preciso resgatar o reconhecimento da obra de arte. Esse resgate se dá através da comunidade em que ela se insere, o envolvimento efetivo, tanto através do conhecimento técnico como cultural dos elementos pétreos, trará o empoderamento necessário para o surgimento de uma ação mais efetiva na conservação da matéria e restauração das obras de arte.

\section{ESTUDO DE CASO - PONTE DA CADEIA}

Localizada em uma região predominantemente montanhosa, na região dos Campos das Vertentes, São João del Rei faz limites com os municípios de Tiradentes, Conceição da Barra de Minas, Ritápolis, Coronel Xavier Chaves, Barbacena, Ibertioga, Madre de Deus de Minas, Nazareno, Santa Cruz de Minas, Carrancas, Piedade do Rio Grande e Prados. É a maior cidade setecentista do estado, dotada de uma vasta gama arquitetônica, na qual não se restringe apenas ao Barroco, na sua parte histórica é possível observar diversas linhas arquitetônicas.

A construção da Ponte da Cadeia, de pedra e cal, foi arrematada, em 24 de fevereiro de 1798, por Joaquim Bernardes Chaves. Este arrematante, um mês depois, cedeu seus direitos a João Gonçalves Gomes, que ficou também com a obrigação de construir dois paredões no correr de um dos pegões.

O primeiro registro que faz menção à ponte é de 1742, quando junto com a compra de ferragens para obra da Cadeia, também foram feitos reparos na ponte defronte, a qual era de madeira, pois o recibo faz menção a um carpinteiro. Em 1745 a Câmara lança o Auto de Arrematação da ponte da cadeia (veja figura 4).

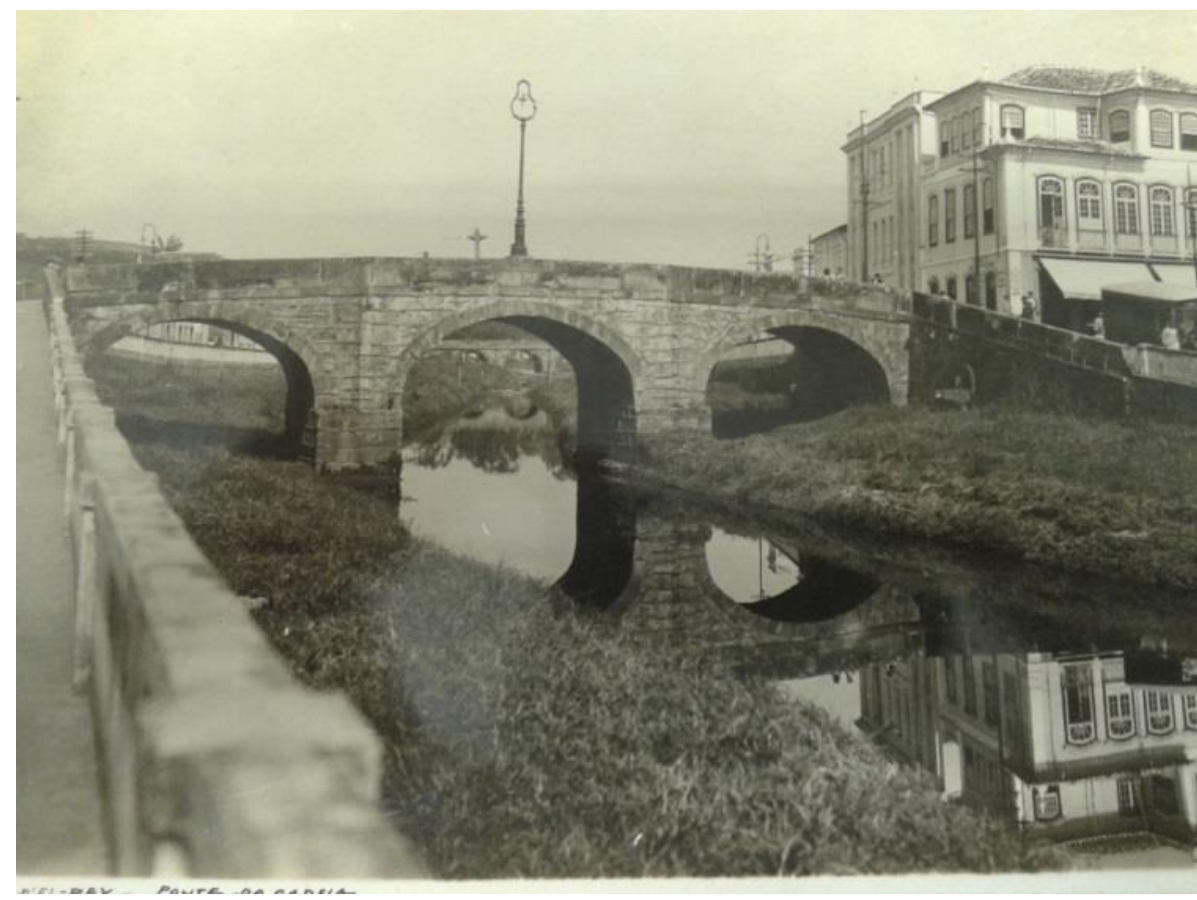

Figura 4. Ponte da Intendência (ou da Cadeia) sobre o Córrego do Lenheiro. Autor: João de Almeida - Fonte: Acervo Iphan-BH 
A Ponte da Cadeia teve anteriormente outras denominações. Primeiro era conhecida como Ponte Nova, talvez por substituir alguma mais antiga ou então ser de construção mais recente em relação à outra, depois passou a ser conhecida como: Ponte Nova da Intendência, Ponte da Intendência, Ponte de Baixo, por ficar abaixo em relação à Ponte do Rosário, e, finalmente, passou a ser chamada de Ponte da Cadeia, desde a mudança da cadeia do Largo do Rosário, em frente ao Passo de N. Sra. da Piedade, para a parte térrea do edifício da Casa da Câmara, atual sede da Prefeitura Municipal. A Lei n.으 469, de 21 de janeiro de 1926, mudou o nome de Ponte da Cadeia para Ponte Municipal, mas a população e mesmo a administração pública, continuam a denominá-la Ponte da Cadeia (veja figura 5).

Os vãos desta ponte são em forma de arco abatido, sarapanel ou asa de cesta. Uma cruz de pedra, formada de hastes oitavadas com raios na junção, encontra-se bem ao meio da ponte, sobre uma peanha introduzida no corrimão.

Em 2001, acontece a primeira grande intervenção no entorno imediato da Ponte da Cadeia, o Córrego Lenheiro passa por intensa intervenção com objetivo de amenizar a cheia durante o período chuvoso.

Em junho de 2001, foi chamada uma equipe técnica para avaliação da Ponte da Cadeia e Ponte do Rosário, ambas em pedra, a solução adotada foi o estreitamento da caixa viária através do alargamento dos passeios, desta forma inviabilizando o trafego de veículos pesados.

É comum que construções antigas sofram depreciações em seus materiais somatizando diversos problemas que comprometem o seu estado de conservação. Estas construções são compreendidas, em sua maioria, por sistemas estruturais autônomos que podem perder sua trabalhabilidade gerando instabilidade.

As intervenções construtivas realizadas ao longo do tempo, contribuem para a degradação da estrutura, como é o caso da inserção de material espúrio ou inserção de elementos de similaridades diferentes do original, tais ações, além de acarretar danos, mudam completamente o diagrama original da ponte. Além do mais, um dos maiores atenuantes do processo depreciativo é decorrente da ausência de uma manutenção efetiva.

\section{MAPEAMENTO DE FORMAS DE ALTERAÇÃO - PONTE DA CADEIA}

A Ponte da Cadeia apresenta trechos em que as pedras de cantaria apresentam alterações cromáticas, trechos com perdas, presença de vegetação, filme negro, intervenções com cimentos, inserções de grampos metálicos e fissuras pontuais (veja as figuras de 6 a 15).

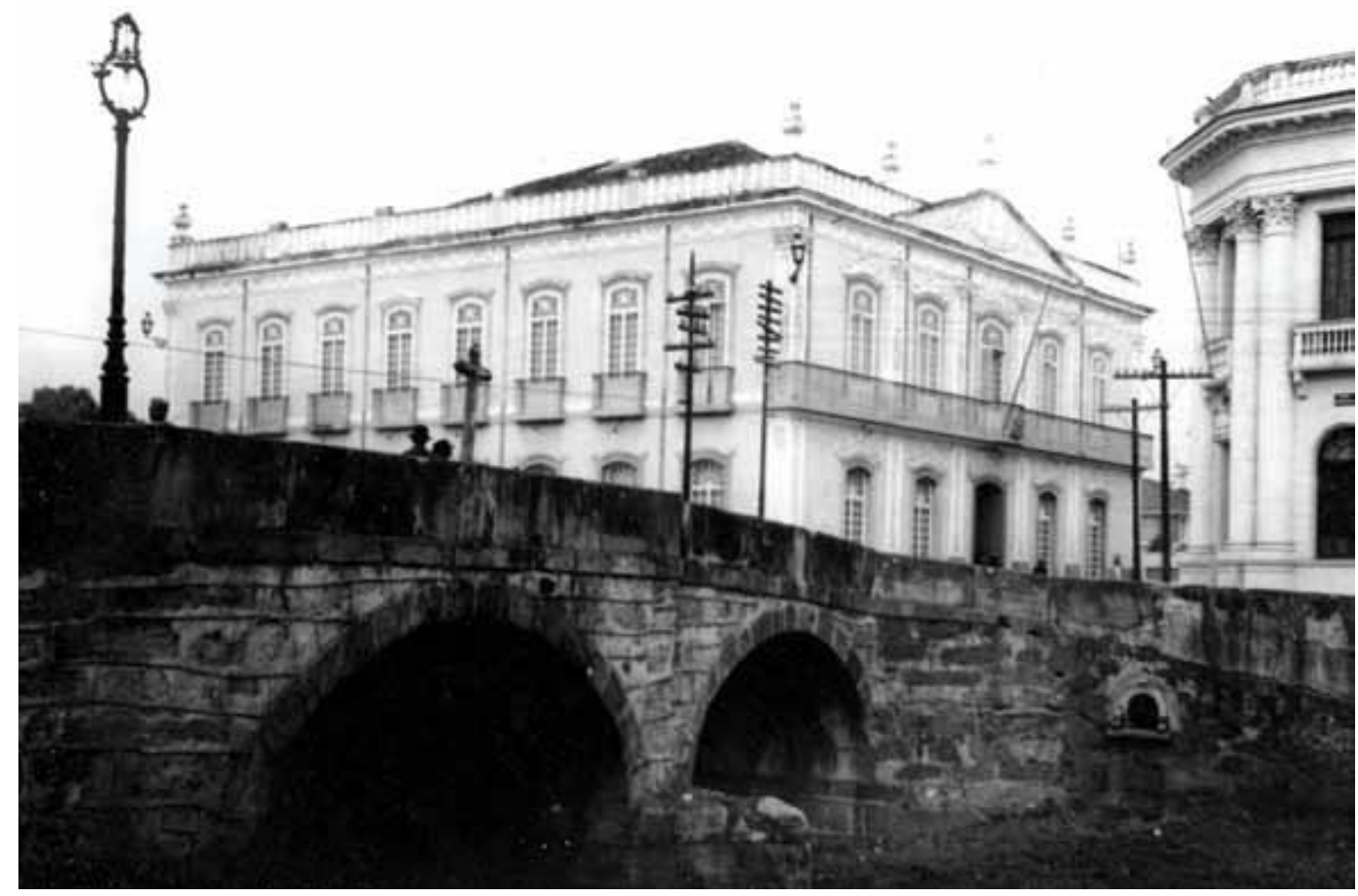

Figura 5. Câmara Municipal, com a Ponte da Intendência (ou da Cadeia) em primeiro plano. Fotografia: T. Halfeld, s/d. - Acervo IPHAN-BH 


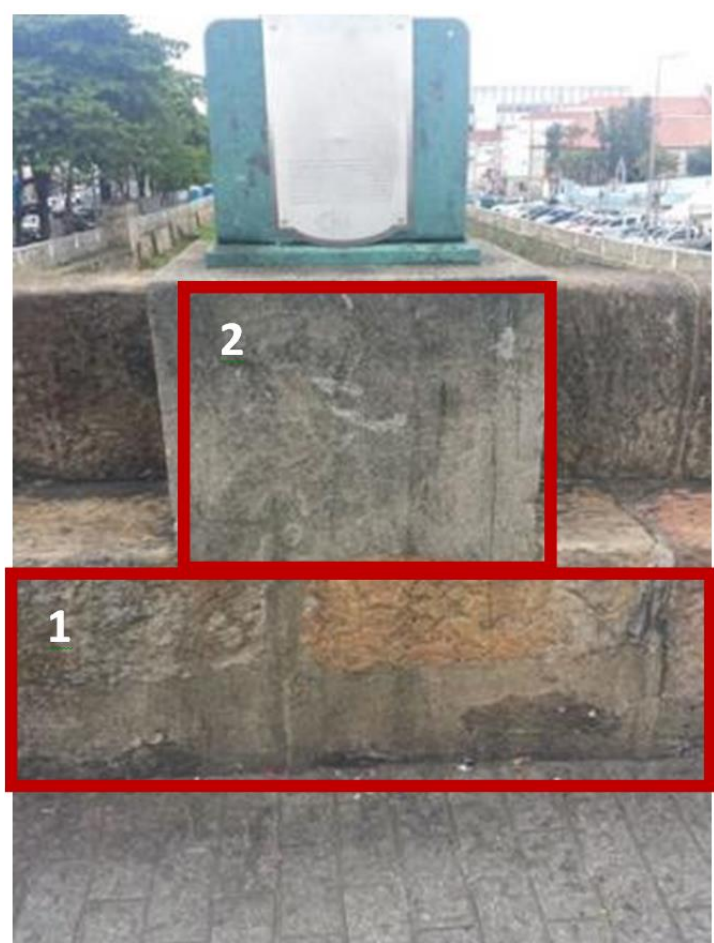

Figura 6. Ponte da Cadeia - Fonte: Consmara Engenharia - Data: 13/01/2015

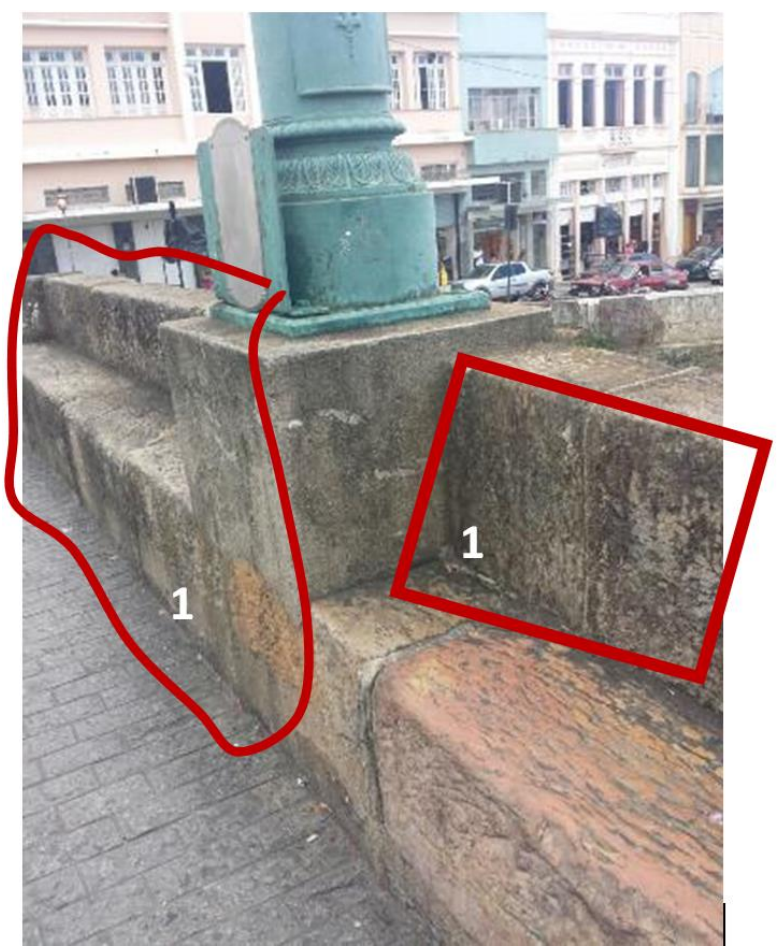

Figura 7. Ponte da Cadeia - Fonte: Consmara Engenharia - Data: 13/01/2015 


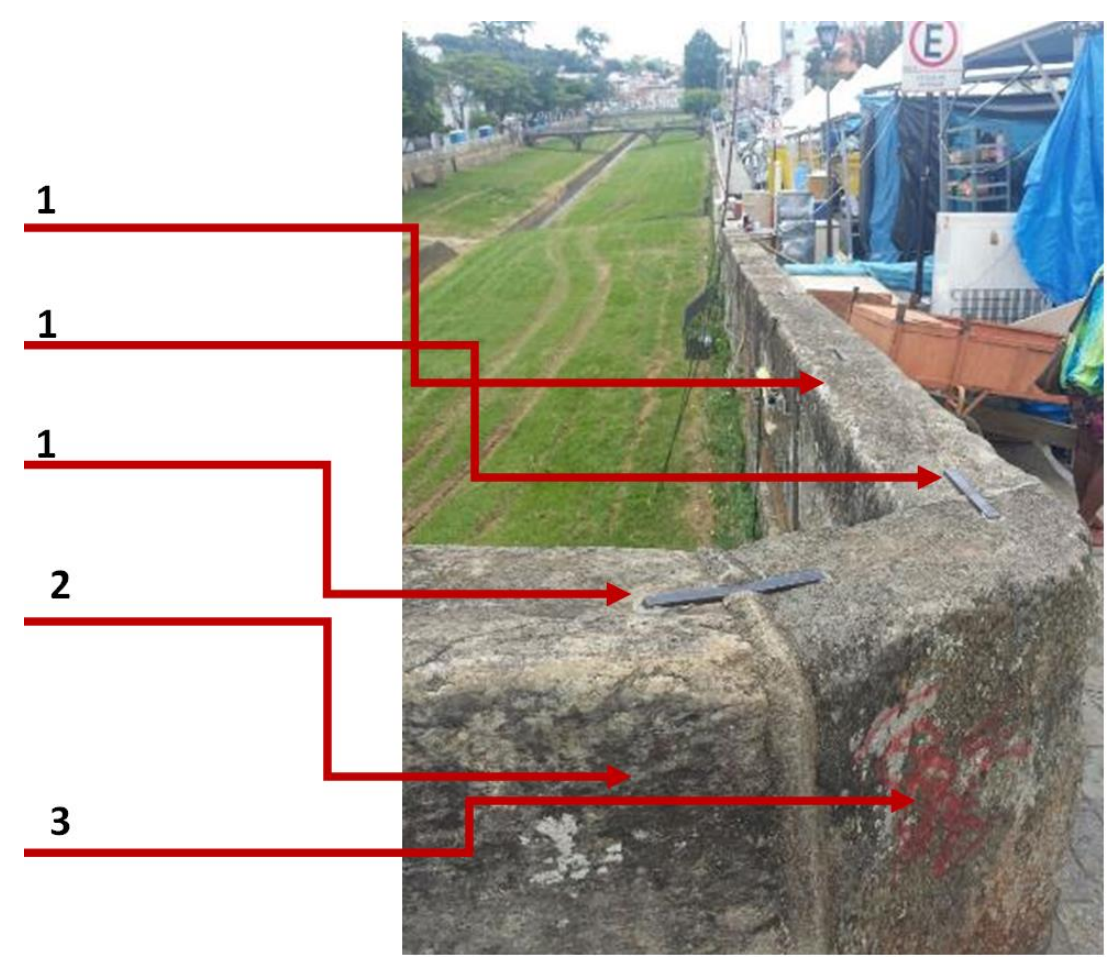

Figura 8. Ponte da Cadeia - Fonte: Consmara Engenharia - Data: 13/01/2015

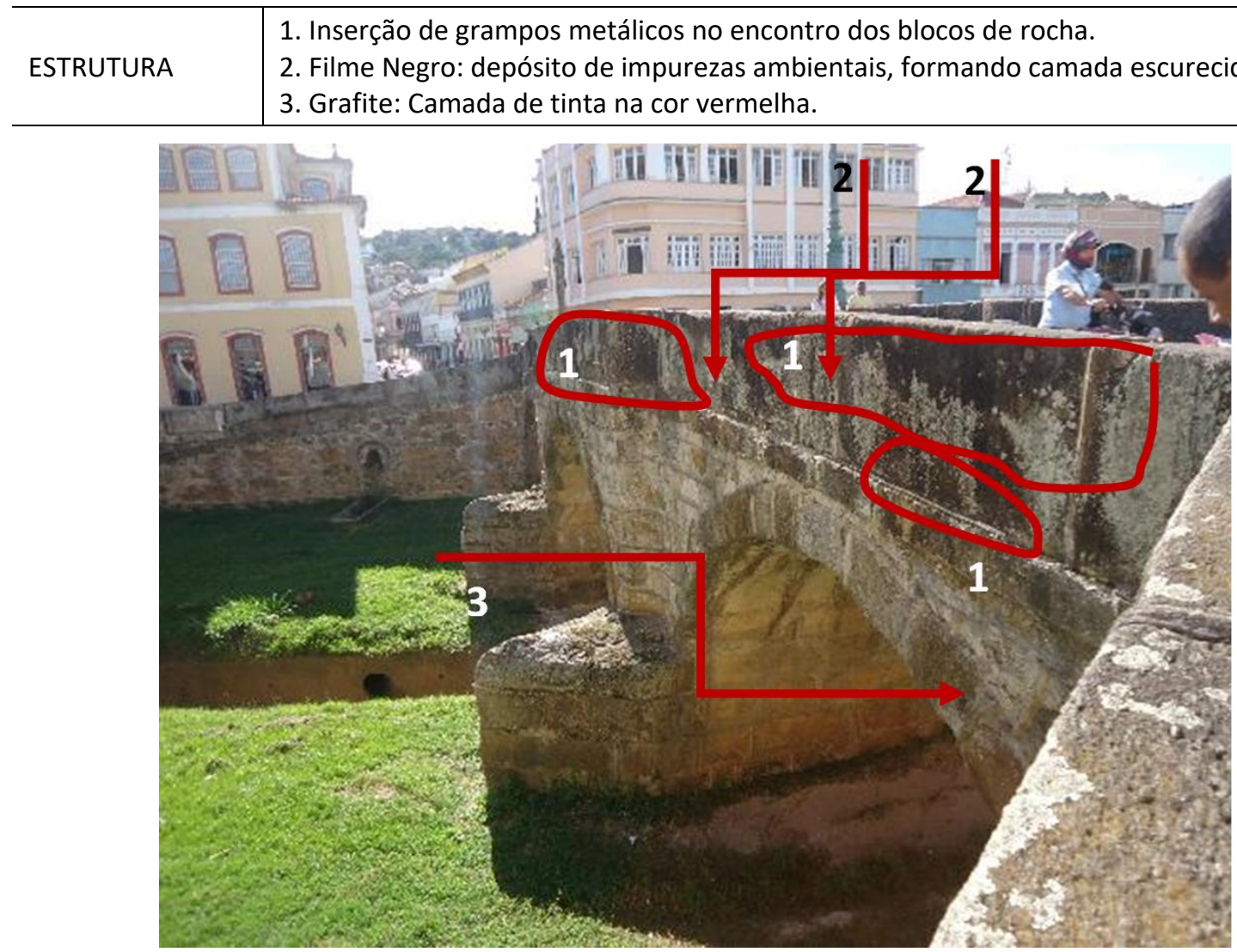

Figura 9. Ponte da Cadeia - Fonte: Consmara Engenharia - Data: 13/01/2015
ESTRUTURA
1. Filme negro: depósito de impurezas ambientais, formando camada escurecida.
2. Eflorescência
3. Acréscimo de argamassa cimentícia na estrutura. 


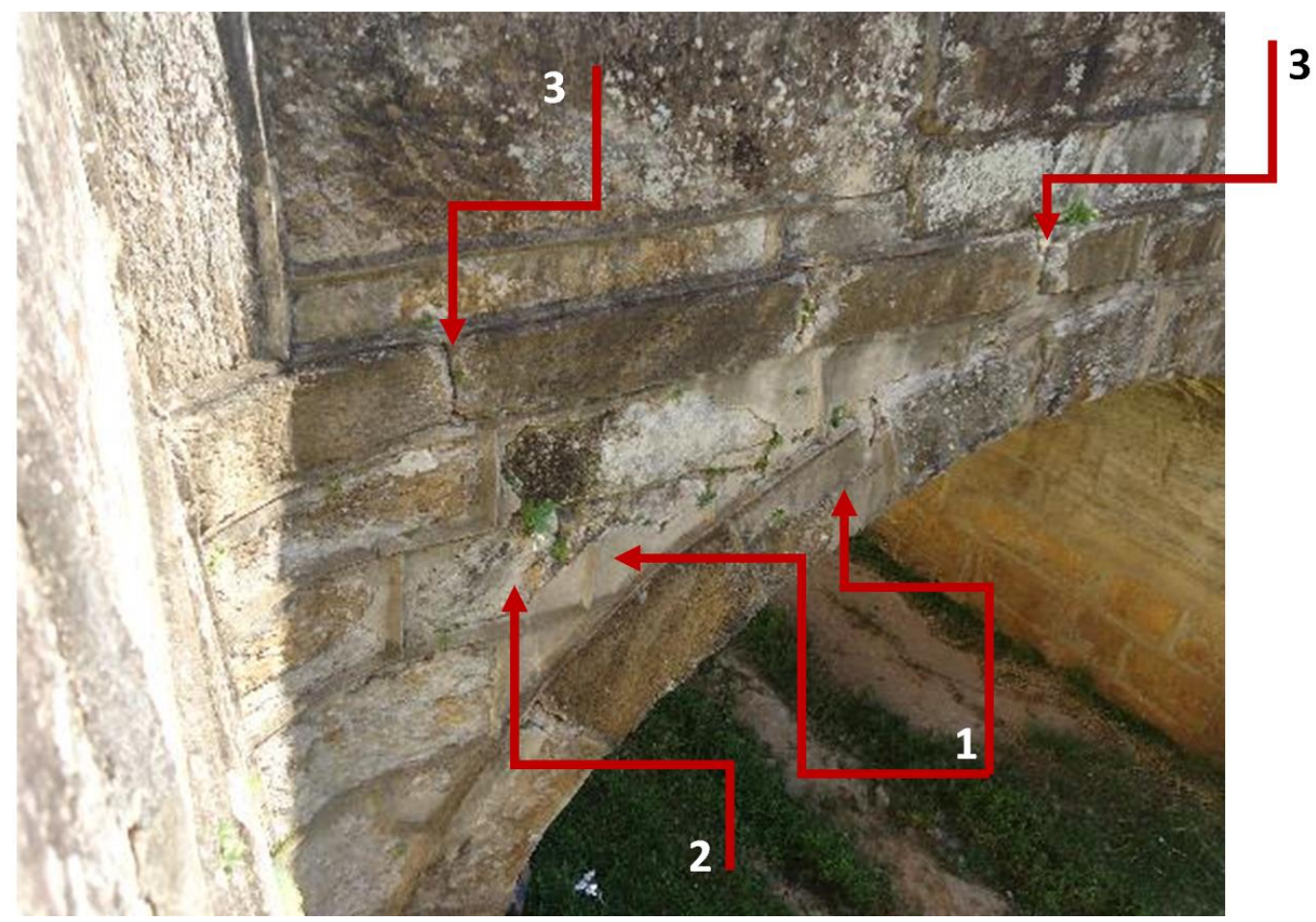

Figura 10. Ponte da Cadeia - Fonte: Consmara Engenharia - Data: 13/01/2015

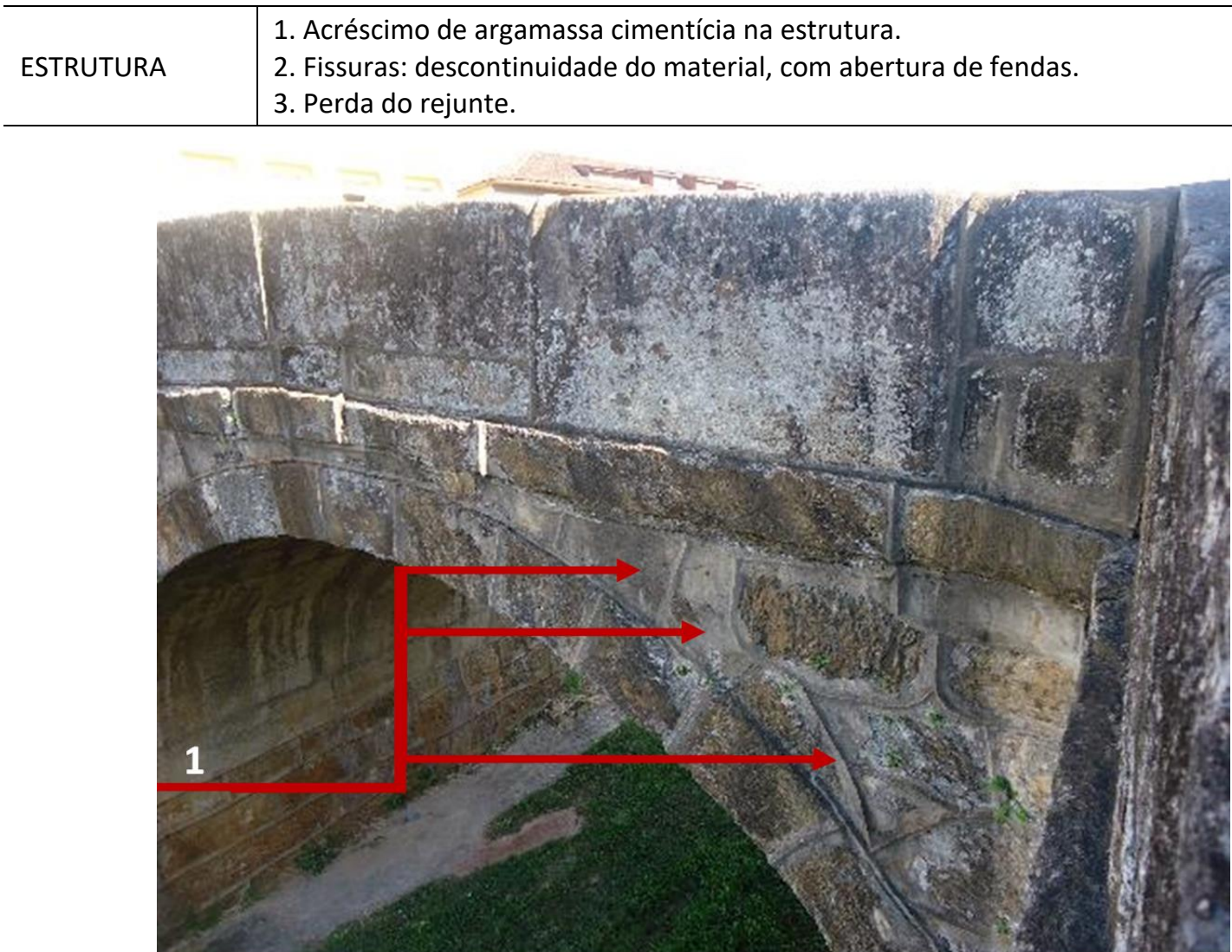

Figura 11. Ponte da Cadeia - Fonte: Consmara Engenharia - Data: 13/01/2015 


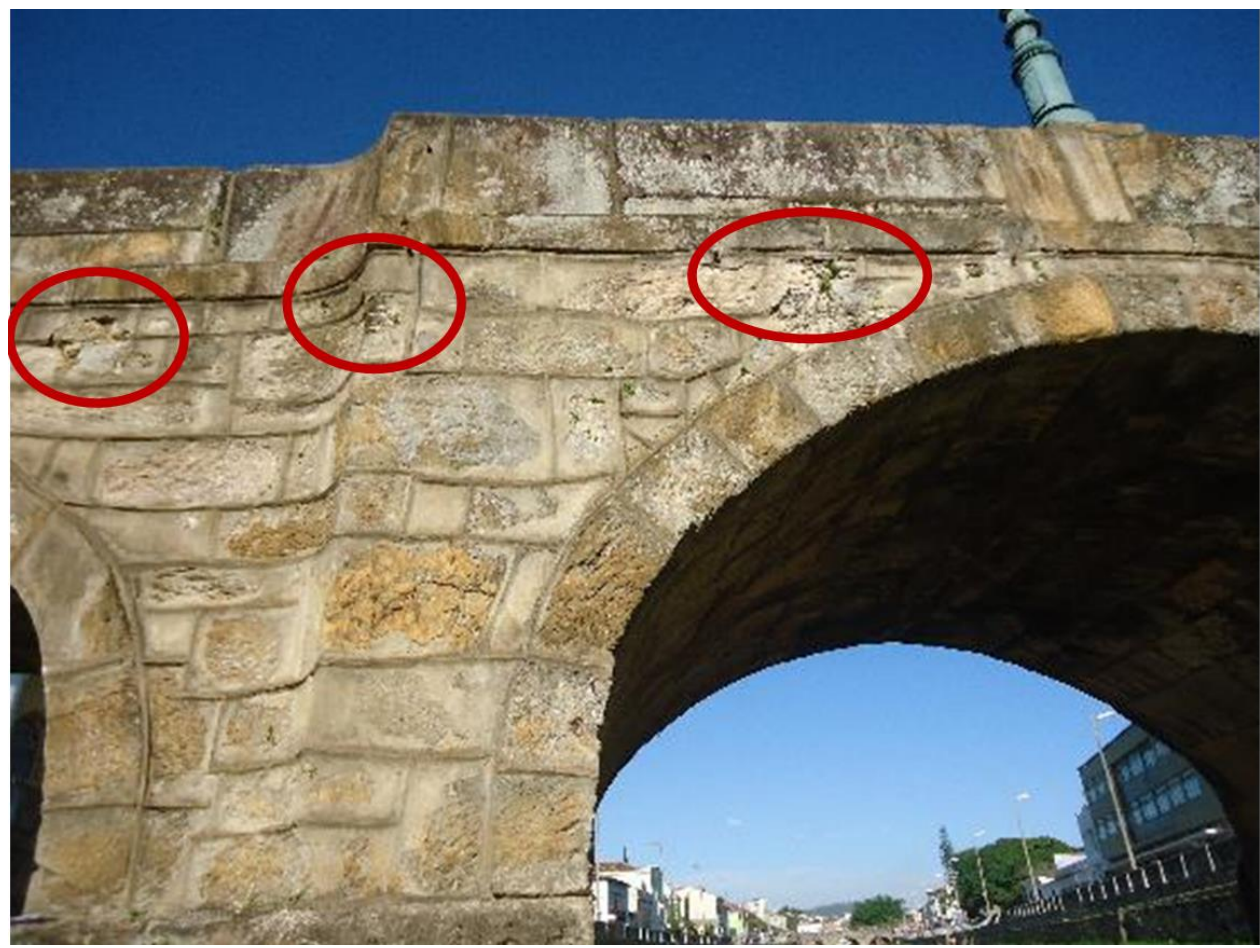

Figura 12. Ponte da Cadeia - Fonte: Consmara Engenharia - Data: 13/01/2015

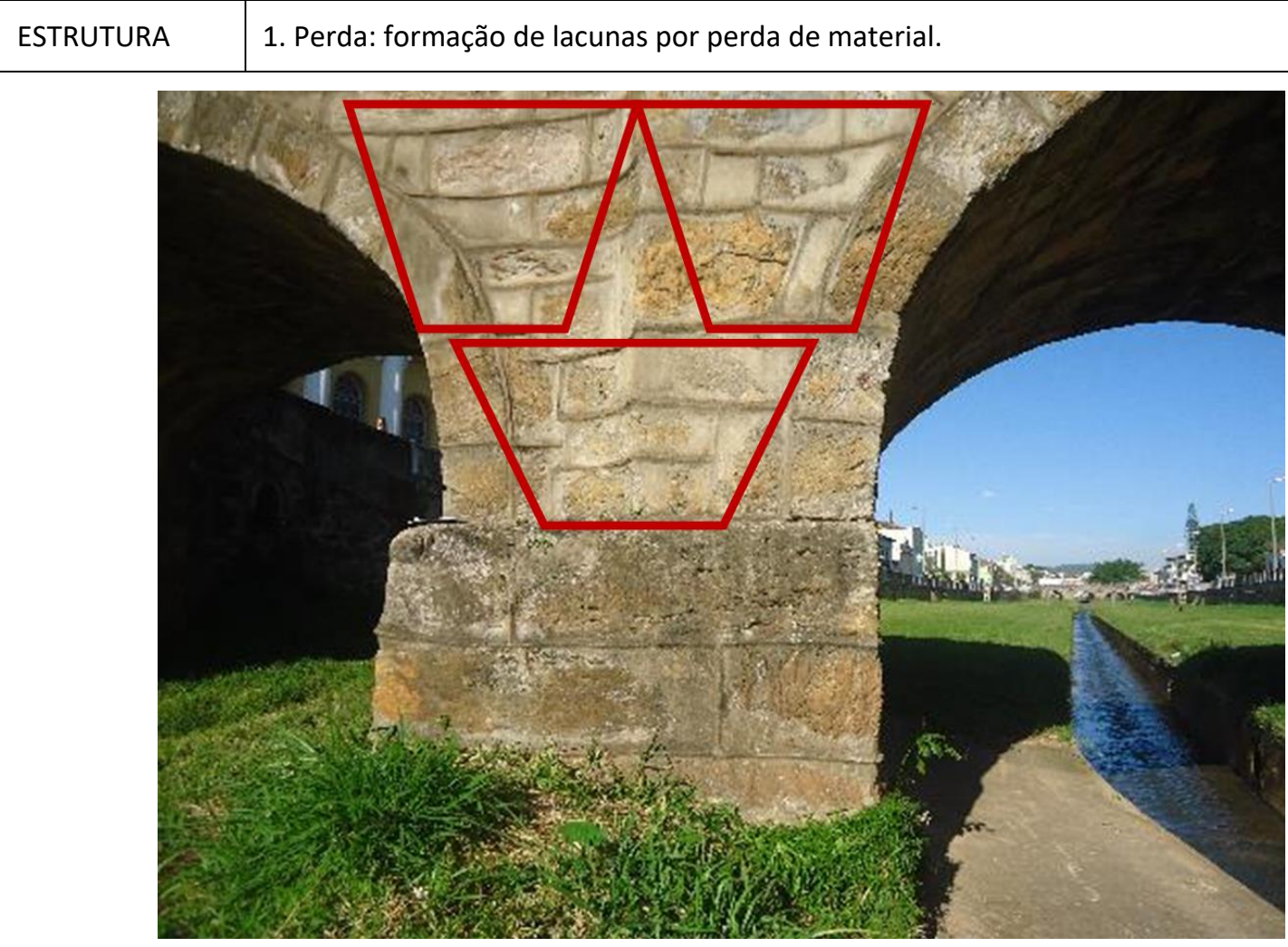

Figura 13. Ponte da Cadeia - Fonte: Consmara Engenharia - Data: 13/01/2015 


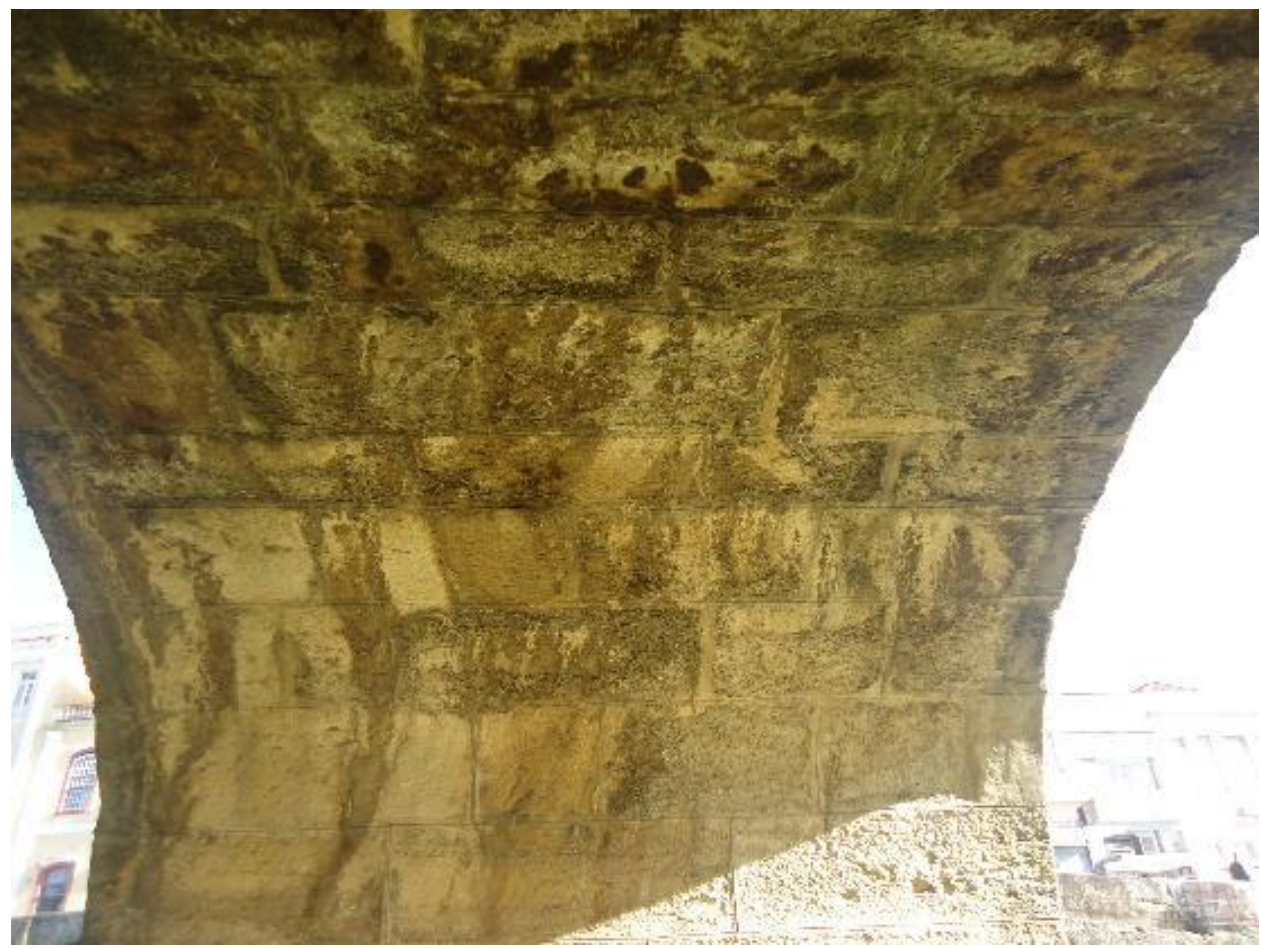

Figura 14. Ponte da Cadeia - Fonte: Consmara Engenharia - Data: 13/01/2015

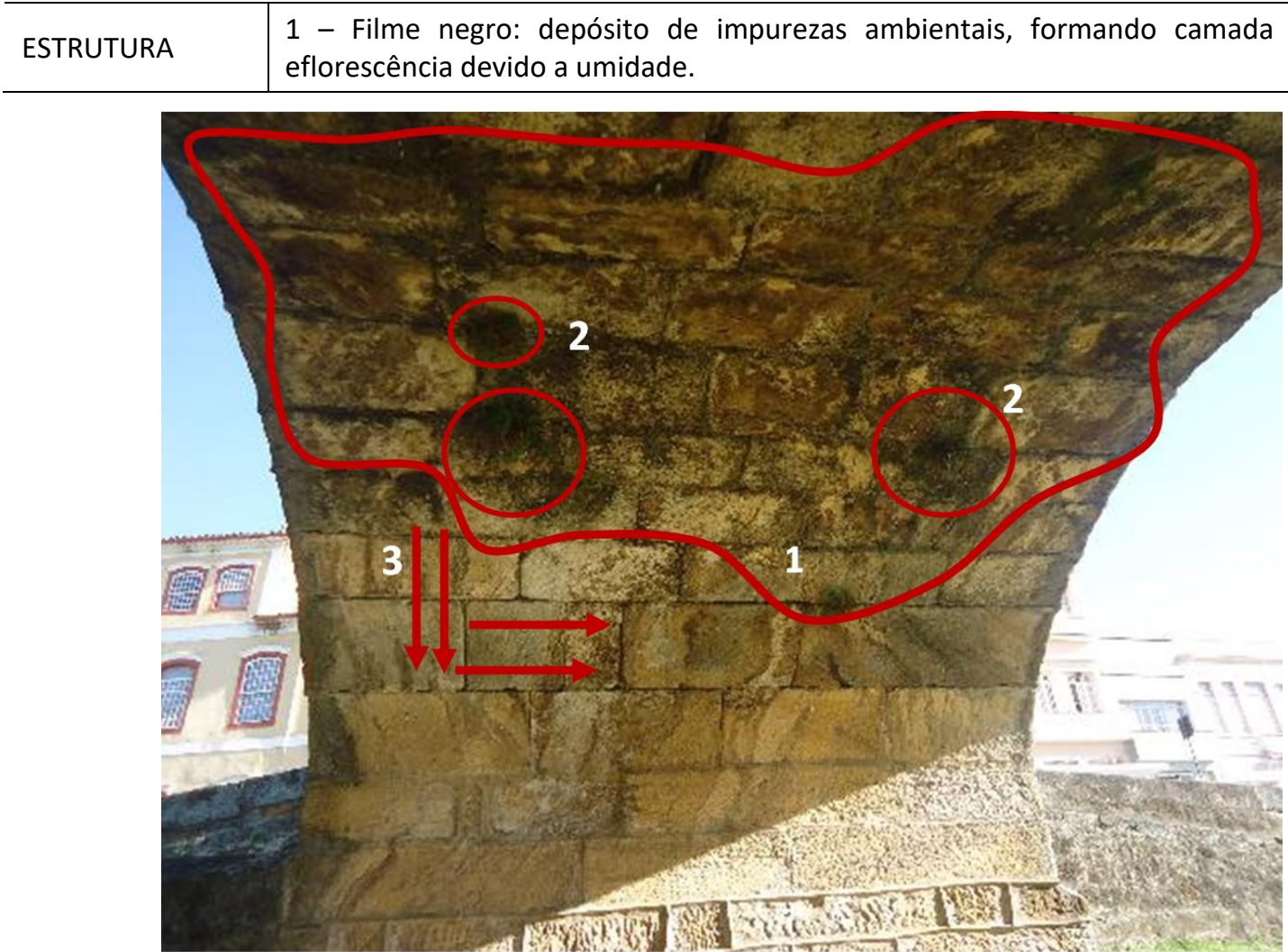

Figura 15. Ponte da Cadeia - Fonte: Consmara Engenharia - Data: 13/01/2015

ESTRUTURA

1 - Filme negro: depósito de impurezas ambientais, formando camada espessa e Eflorescência devido a umidade.

2 - Presença de Vegetação de pequeno porte

3 - Perda do rejunte. 


\subsubsection{Panorama Geral}

Segundo Isaias (2011), a grande maioria das manifestações patológicas apresenta sintomas característicos que permitem determinar a sua origem, as causas que conduziram ao seu aparecimento e as consequências que poderão ocorrer caso não sejam devidamente corrigidas. As causas das patologias encontradas na Ponte da Cadeia envolvem, fatores diversos.

Estresses externos: Ação com tensões localizadas, conforme a solicitação de carregamento a que está submetida. Os esforços, em outrora aplicados sobre a estrutura, através do tráfego de veículos de pequeno e médio porte, provocaram deformações (perda de material) e microfissuras na estrutura, o que atualmente foi amenizado através da diminuição do carregamento submetido na estrutura pois os veículos de médio porte estão proibidos de trafegar sobre a mesma. Aponta-se aqui que o ideal seria manter o tráfego apenas de transeuntes sobre a estrutura da ponte.

Estresses internos: A cristalização de sais é um dos maiores fatores de degradação dos materiais porosos. Os sais solúveis se instalam nos poros da pedra, cristalizam-se pelo processo de evaporação e passam do estado líquido para sólido, expandindo-se internamente dentro dos poros e causando tensões internas. Devido principalmente pela umidade ascendente.

\section{Agentesfísico-químicos externos:}

1 - Capilaridade, processo de sucção de água que alimenta a umidade das paredes e juntamente com ela os sais solúveis.

2 - Poluição atmosférica: Ar poluído geralmente com grandes concentrações de dióxido de enxofre, o qual junto com a água e o oxigênio do ar, transforma-se em ácido sulfúrico, o qual causa danos a estrutura e escurecendo-a, a presença defilme negro presente na estrutura é um fator da camada de poluentes e fuligens que vão se acumulando com o tempo.

\section{Ataques Biológicos:}

1 - Bactérias e Fungos: Várias bactérias e fungos captam energia para sua sobrevivência através de reações químicas, como resultado, aparecem formações de ácidos que podem corroer os materiais de construção e até mesmo a pedra.

2 - Plantas: De pequenoporte, podem causar rupturas e destruição da cantaria. A planta se desenvolve ao penetrar na alvenaria: as raízes e o caule se expandem, aumentando de volume e causando a consequente destruição dos materiais ali presentes.

A desagregação granular é uma patologia que se encontra em algumas regiões pontuais da estrutura, já a colonização biológica afeta grandes áreas da estrutura, os quais observavam-se alguns filmes biológicos de cor negra ou castanha escura, de pequena espessura e fortemente aderentes a estrutura.

Há várias juntas abertas em toda área da estrutura. Grande número de juntas encontra-se preenchida com argamassas de cimento Portland, sendo evidente a sua ação prejudicial nas zonas adjacentes das pedras, contribuindo para o incremento da queda de material pétreo e conduzindo a uma desagregação granular diferencial.

A maior parte das eflorescências é pulverulenta, de cor branca ou bege, formando-se predominantemente nas zonas mais baixas (sob os arcos) submetidas à ascensão por capilaridade e cristalização de minerais de sais solúveis, por estarem frequentemente ligadas a maior exposição a umidade.

Logo podemos concluir que uma estratégia adequada de inspeção e de manutenção poderá proporcionar à estrutura um melhor desempenho global em toda a sua vida útil.

\section{CONCLUSÃO}

Normalmente, os métodos preventivos usados para a detecção de danos de edificações são baseados em informações coletadas em campo por meio de inspeções diretas sobre a edificação, e tais detecções podem ser executadas por brigadas formadas por pessoas da comunidade, assim visando a segurança do patrimônio histórico. É de grande importância que as comunidades destes sítios que abrigam as obras de arte passem a ter um novo olhar, uma nova concepção da importância de tais elementos que sofreram mutações, tanto físicas como sociais pela produção capitalista.

A participação da comunidade é de grande importância na conservação do patrimônio, estabelecendo uma metodologia e treinamento que qualifique tais pessoas para realizarem tarefas preventivas tais como: levantamento de dados, emissão de relatórios, limpeza preventiva, orientação ao público.

Assim o novo será o agente mantenedor do passado, tornando-o referência, não somente em monumentalidade, mas em símbolo de importância histórica e esta será a principal ferramenta para a manutenção e preservação do patrimônio histórico edificado.

\section{REFERÊNCIAS BIBLIOGRÁFICAS}

BRANDI, Cesare. Teoria da restauração. Cotia: Ateliê, 2004.

COSTA, Lucio. Arquitetura. Ed. José Olympio, 2002.

CUNHA, Eurivaldo, CESAR, Edson. Brigadas de combate a incêndio. Brasília: Eixo, 1982. 
GAMA, Ruy. Engenho \& Tecnologia. São Paulo, Duas Cidades, 1983.

ISAIAS, G. C. Livro: Concreto: Ciência e Tecnologia. Volume 2. 1a ed. IBRACON - Instituto Brasileiro do Concreto - Editor: Geraldo Cechella Isaias. São Paulo. 2011.

KATINSKY, Júlio R. Um guia para a história da técnica no Brasil Colônia. São Paulo: Fau-USP, 1998).

KATINSKY, Julio R. Uso de pedras duras nas construções brasileiras. Primeiro Congresso do Fórum Matosinhense. Matosinhos, 27 de marco de 1993.

MOTOYAMA, Shozo. Perlúdio para uma História da Ciência e Tecnologia no Brasil. São Paulo: EDUSP; FAPESP, 2004).

SEITO, Alexandre Itiu et al. A segurança contra incêndios no Brasil. São Paulo: Projeto, 2008.

SILVA, Elvan. Matéria, idéia e forma: uma definição de arquitetura. Porto Alegre: Ed. UFRGS, 1994.
VARGAS, Minton (org.). História da Técnica e da Tecnologia no Brasil. São Paulo: EDUNESP; CEETEPS, 1994).

VASCONCELLOS, Sylvio de. ARQUITETURA NO BRASIL: Sistemas Construtivos. Belo Horizonte: Escola de Arquitetura/UFMG, 1958.

Contribuição ao

1‥ Simpósio Brasileiro de Caracterização e Conservação da Pedra 14 a 16 de dezembro de 2016, Congonhas - MG

Nota:

É de responsabilidade da comissão editorial do Simpósio a revisão gramatical, ortográfica, de citações e referências bibliográficas. As normas de submissão podem se diferenciar das desta revista. 